\title{
Comparative chemistry of unsaturated compounds of Group 14 elements*
}

\author{
Mitsuo Kira \\ Department of Chemistry, Graduate School of Science, Tohoku University, Aoba-ku \\ Sendai, 980-8578, Japan
}

\begin{abstract}
Structures and reactions of a stable dialkylsilylene and various cyclic and acyclic disilenes, which we have recently synthesized, are discussed in detail. The stable silylene was found to be well protected sterically from dimerization but least perturbed electronically as evidenced by UV-vis and NMR spectroscopy. Persilylated acyclic and cyclic disilenes have shown interesting features in the $\mathrm{Si}=\mathrm{Si}$ bond distances, electronic spectra, and reactions, due to the remarkable electronic and steric effects of trialkylsilyl substituents. Detailed theoretical calculations for the addition of water to disilene has shown that the intramolecular antiaddition pathway is rationalized using the orbital symmetry rule. The reactions of disilenes with haloalkanes were judged to proceed via the rate-determining halogen abstraction of disilenes from haloalkanes. The biradical character of disilenes may be related to the small $\pi$ bond energy.
\end{abstract}

\section{INTRODUCTION}

One of the main subjects of the chemistry of Group 14 organometallic compounds has been comparing their structure and reactivity with those of the corresponding organic compounds to examine the validity of the methods and concepts of physical organic chemistry. There have been revealed remarkable points of similarity and difference in the structure and reactions between organic compounds and the corresponding heavier Group 14 element compounds. To explain the origin of these points based on the underlying common principles and rationale among Group 14 element compounds is expected to contribute to the innovation of physical organic chemistry. A successful case has been realized in the Carter-Goddard-Malrieu-Trinquier (CGMT) theory [1,2]. Whereas the geometry of $\mathrm{H}_{2} \mathrm{C}=\mathrm{CH}_{2}$ is planar around the double bond, $\mathrm{H}_{2} \mathrm{M}=\mathrm{MH}_{2}(\mathrm{M}=\mathrm{Si}, \mathrm{Ge}$, and $\mathrm{Sn})$ are predicted theoretically to be transbent around the $\mathrm{M}=\mathrm{M}$ double bonds, and the dimer of $\mathrm{H}_{2} \mathrm{~Pb}$ : does not have direct bonding between two lead atoms any more but hydrogen-bridged cyclic structure. According to the CGMT theory, the origin of the geometrical characteristics is explained by the singlet-triplet separations $\left(\Delta \mathrm{E}_{\mathrm{ST}} ; \mathrm{E}\right.$ (triplet)- $\mathrm{E}$ (singlet)) of $\mathrm{H}_{2} \mathrm{M}$ : and the double-bond energies of $\mathrm{H}_{2} \mathrm{M}=\mathrm{MH}_{2}\left(\mathrm{E}_{\sigma+\pi}\right)$ (Fig. 1). $\mathrm{R}_{2} \mathrm{M}=\mathrm{MR}_{2}$ are predicted to be planar for $\Delta \mathrm{E}_{\mathrm{ST}}<\mathrm{E}_{\sigma+\pi} / 4$ but trans-bent for $\mathrm{E}_{\sigma+\pi} / 2>\Delta \mathrm{E}_{\mathrm{ST}}>\mathrm{E}_{\sigma+\pi} / 4$; the dimer of $\mathrm{R}_{2} \mathrm{M}$ : should be a doubly bridged cyclic dimer if $\Delta \mathrm{E}_{\mathrm{ST}}>\mathrm{E}_{\sigma+\pi} / 2$ [2]. Applicability of the theory through the whole series of Group 14 elements has stimulated us to compare the structure and reactivity among Group 14 element analogs of fundamental organic compounds such as carbenes and alkenes more in detail to obtain a better understanding of the principles and rules which lie behind the results. Herein, the interesting features of the structures and reactions of a stable dialkylsilylene and various cyclic and acyclic disilenes, which we have recently synthesized, are compared with those of the related organic compounds.

*Plenary lecture presented at the $15^{\text {th }}$ International Conference on Physical Organic Chemistry (ICPOC 15), Göteborg, Sweden, 8-13 July 2000. Other presentations are published in this issue, pp. 2219-2358. 


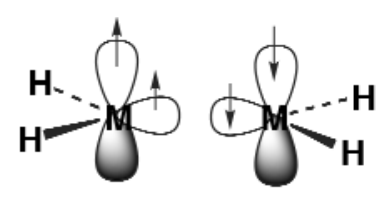

$\mathbf{M}=\mathbf{C}$

Planar

$$
\Delta \mathbf{E}_{\mathrm{ST}} \leq\left(\mathbf{1 / 4 )} \mathbf{E}_{\sigma+\pi}\right.
$$

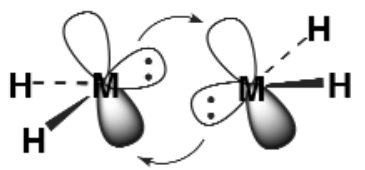

$\mathrm{M}=\mathrm{Si}, \mathrm{Ge}, \mathrm{Sn}$

Trans-Bent

$(1 / 2) \mathbf{F}_{\sigma+\pi} \geq \Delta \mathbf{F}_{S T} \geq(1 / 4) \mathbf{F}_{\sigma+\pi}$

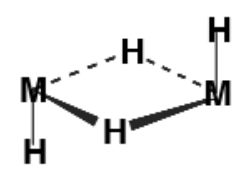

$\mathbf{M}=\mathbf{P b}$

Doubly Bridged

Fig. 1 Schematic representation of the structures of dimers of $\mathrm{MH}_{2}$.

\section{A STABLE DIALKYLSILYLENE}

For a long time, silylenes as well as carbenes were considered only as short-lived species to be observed by spectroscopic methods either in the gas phase or low-temperature matrices, with an exception of decamethylsilicocene having pentahapto-cyclopentadienyl ligands [3], while the divalent dicoordinate species of germanium, tin, and lead have been well characterized as stable molecules. Although several stable carbenes [4] and silylenes [5] have recently been isolated, they are stabilized by the strong interaction between the vacant $\mathrm{p} \pi$-orbital at the divalent atom and filled $\pi$-type orbitals of nitrogen or phosphorus atoms, and hence, their electronic nature is strongly modified from the parent divalent species. 2,2,5,5-Tetrakis(trimethylsilyl)silacyclopentane-1,1-diyl (1) was synthesized as the first dialkylsilylene, which is well protected sterically from dimerization but least perturbed electronically; the intrinsic properties of silylene are entirely embodied in $\mathbf{1}$ [6].

Dialkylsilylene 1 was synthesized as air- and moisture-sensitive orange crystals in $74.5 \%$ yield by the reduction of dibromosilane $\mathbf{2}$ with potassium graphite $\left(\mathrm{KC}_{8}\right)$ in THF (eq. 1). The structure of $\mathbf{1}$ was characterized by $\mathrm{X}$-ray crystallography and UV-vis and NMR spectroscopies.

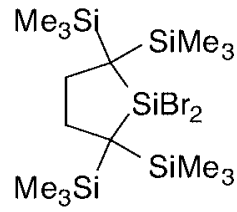

2

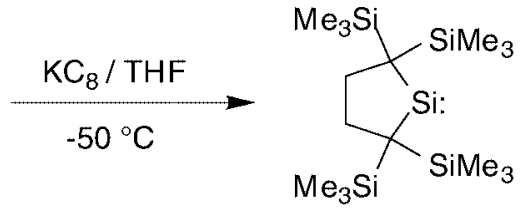

1

The ${ }^{29} \mathrm{Si}$ resonance for the divalent silicon in $\mathbf{1}\left(+567.4 \mathrm{ppm}\right.$ in benzene- $\left.\mathrm{d}_{6}\right)$ is the lowest field resonance reported to date. Although the electron-donation to the formally vacant $\mathrm{Si}$-orbital from the neighboring $\mathrm{C}-\mathrm{Si} \sigma$ bonding orbitals ( $\sigma-\pi$ conjugation) may be significant in $\mathbf{1}$, the extent is far smaller than the electronic perturbation by amino substituents in the stable $\mathrm{N}$-heterocyclic silylenes, as indicated by the less perturbed $n(\mathrm{Si})-3 \mathrm{p} \pi(\mathrm{Si})$ band maximum $\left(\lambda_{\max } 440 \mathrm{~nm}, \varepsilon 500\right)$ and the very low-field ${ }^{29} \mathrm{Si}$ resonance of the divalent silicon.

Facile 1,2-migration of a trimethylsilyl group in $\mathbf{1}$ occurs thermally to give the corresponding silaethene derivative $\mathbf{3}$ (eq. 2). The isomerization is not an intermolecular but an intramolecular process. Preliminary kinetic studies of the isomerization revealed the first-order decay of $\mathbf{1}$ with the rate constant of $1.82 \times 10^{-6} \mathrm{~s}^{-1}$ at $293 \mathrm{~K}, \Delta H$ of $21.1 \mathrm{kcal} / \mathrm{mol}$, and $\Delta S$ of $-12.2 \mathrm{cal} \mathrm{mol}^{-1} \mathrm{~K}^{-1}$. The observed activation enthalpy is close to the theoretical prediction by Nagase et al. [7], who have found that the barrier for the silylene-silaethene isomerization involving 1,2-silyl migration $(24.8 \mathrm{kcal} / \mathrm{mol})$ is much smaller than that for the related 1,2-hydrogen $(43.0 \mathrm{kcal} / \mathrm{mol})$ and 1,2-methyl migrations 
(44.4 kcal/mol) at the MP3/6-31G* level. In contrast, the corresponding stable germylene and stannylene show no such isomerization even at $100{ }^{\circ} \mathrm{C}$. Since the migratory aptitude seems to be governed by the strength of the formed $\mathrm{M}=\mathrm{C}$ double bonds, it is suggested that the corresponding carbene if produced will isomerize rapidly to the corresponding cyclopentene derivative (the Bamford-Stevens reaction), and hence, will be hard to be isolated.

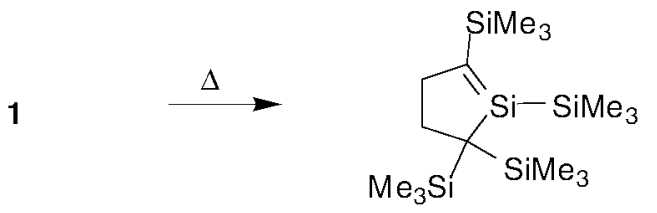

3

Silylene 1 reacts with various substrates including methanol, methyl iodide, ethylene, bis(trimethylsilyl)acetylene, and 2,3-dimethyl-1,3-butadiene to give the corresponding adducts almost quantitatively (eqs. 3 and 4). Interestingly, 1 reacts with benzene under irradiation to afford the corresponding silaheptatriene (silepin), while $\mathbf{1}$ does not react with benzene in the dark (eq. 5). Whereas the thermal addition of a silylene with benzene has been reported [8], the present result constitutes the first example of the reaction of excited-state silylene. The mechanistic details are now under investigation.

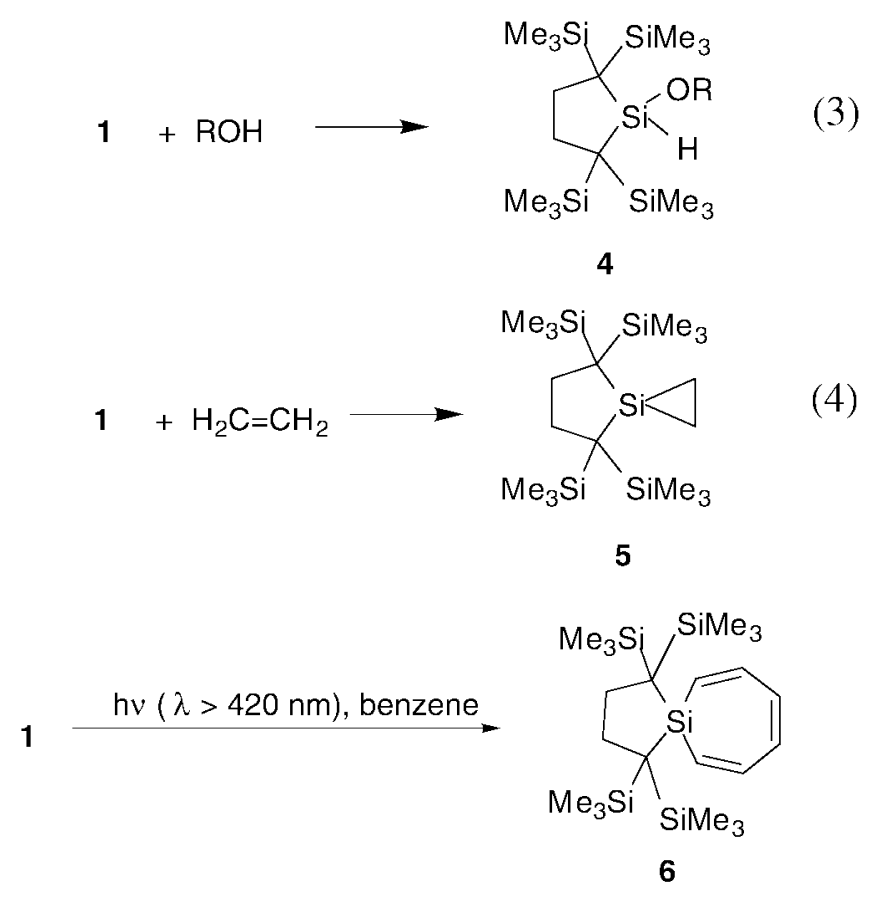

\section{STABLE CYCLIC DISILENES}

The existence of a variety of structural types such as cycloalkenes, conjugated polyenes, cumulenes, and aromatic compounds is responsible for the rich chemistry of $\mathrm{C}=\mathrm{C}$ double bonds. In contrast, various types of the silicon analogs of alkenes are still missing and remain to be actively investigated [9]. We have isolated several tetrakis(trialkylsilyl)disilenes $\mathbf{7 a - 7 d ~ [ 1 0 ] , ~ p e r s i l y l a t e d ~ c y c l o t r i s i l e n e ~} 8$ [11], cyclotetrasilene 9 [12], and very recently spiropentasiladiene 10 [13]. Due to the remarkable electronic and steric effects of trialkylsilyl substituents, these disilenes show interesting features in the $\mathrm{Si}=\mathrm{Si}$ bond distances, electronic spectra, and reactions. 
<smiles>[R][Si]([R])=[Si]([R])[R]</smiles>

$$
\begin{aligned}
& 7 \mathrm{a}, \mathrm{R}=\mathrm{R}^{\prime}=i-\mathrm{Pr}_{2} \mathrm{MeSi} \\
& 7 \mathbf{b}, \mathrm{R}=\mathrm{R}^{\prime}=t-\mathrm{BuMe}_{2} \mathrm{Si} \\
& 7 \mathbf{c}, \mathrm{R}=\mathrm{R}^{\prime} i=i-\mathrm{Pr}_{3} \mathrm{Si} \\
& 7 \mathrm{~d}, \mathrm{R}=i \mathrm{Pr}_{2} \mathrm{MeSi}^{\prime}, \mathrm{R}^{\prime}=t-\mathrm{BuMe}_{2} \mathrm{Si}
\end{aligned}
$$
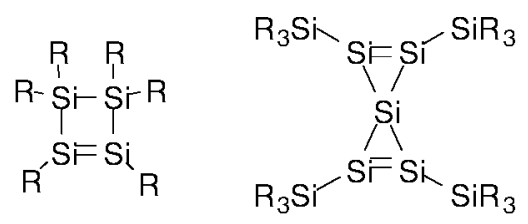

9, $\mathrm{R}=t-\mathrm{BuMe} \mathrm{Si}$

10, $\mathrm{R}=t-\mathrm{BuMe}_{2} \mathrm{Si}$

Cyclic disilenes 8 and 9 isomerize under irradiation to give 11, which reverts thermally to 9 (eq. 6). The thermal isomerization from $\mathbf{1 1}$ to $\mathbf{9}$ as well as the photochemical isomerization from $\mathbf{9}$ to 11 was confirmed to proceed via 1,2-silyl migration using the labeled compounds [12b].

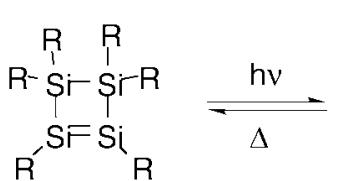

9

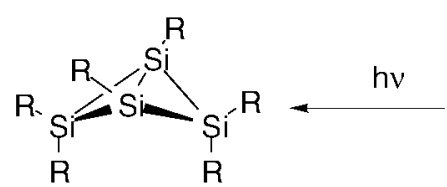

11<smiles>[R][SiH]1[SiH][SiH]1[BH2-]</smiles>

8

\section{MECHANISMS OF WATER ADDITION TO DISILENE}

In contrast to $\mathrm{C}=\mathrm{C}$ double bonds, $\mathrm{Si}=\mathrm{Si}$ double bonds have been known to react with various alcohols and phenols very smoothly without catalysts to give the corresponding adducts [9,14]. Although much attention has been focused on the mechanisms of the unique addition reactions of disilenes, the origin of the diverse stereochemical outcome is still controversial. One of the most intriguing stereochemical results has recently been given by Apeloig and Nakash [15], who showed that the addition of $p$ methoxyphenol to tetramesityldisilene was syn-selective in toluene but anti-selective in polar tetrahydrofuran (THF), even at the low alcohol concentration; the anti-adduct was explained by the rotation around the $\mathrm{Si}-\mathrm{Si}$ bond in the zwitterionic intermediate followed by fast intramolecular proton transfer.

To elucidate the origin of the stereochemical diversity of the alcohol addition to disilenes found experimentally, we have examined theoretically the detailed pathways of the disilene-water addition as a model reaction. Two different reaction pathways via two weak complexes $\mathrm{C}_{\mathrm{S}}$ and $\mathrm{C}_{\mathrm{A}}$ were found competitive. The electrophilic approach of a water hydrogen to a silicon in complex $\mathrm{C}_{\mathrm{A}}$ should occur through the interaction between water lowest unoccupied molecular orbital (LUMO) $\left(\sigma^{*}\right)$ and the disilene highest occupied molecular orbital (HOMO) $(\pi)$. The least motion pathway to give the syn adduct is symmetry forbidden, while the sterically disfavored antara-facial approach of the hydrogen to the $\mathrm{p} \pi$ lobe of the opposite side of the disilene $\pi$ plane is allowed, similarly to the [2+2] cycloaddition (Fig. 2a). Actually, the electrophilic attack of water hydrogen causes the rotation around the Si-Si bond, leading to the anti-adduct (Fig. 3a). In the transition structure $\mathrm{TS}_{\mathrm{A}}$, the two $\mathrm{H}_{2} \mathrm{Si}$ planes are almost perpendicular to each other; the angle between two norms to two respective $\mathrm{H}_{2} \mathrm{Si}$ planes is $83.5^{\circ}$. On the other hand, from another weak complex $\left(\mathrm{C}_{\mathrm{S}}\right)$, the nucleophilic attack of water to disilene occurs via the interaction of water HOMO (n) with disilene LUMO ( $\left.\pi^{*}\right)$ (Fig. 2b). Since the oxygen $\mathrm{n}$ orbital is almost orthogonal to the $\mathrm{p} \pi$ orbital on the approaching $\mathrm{Si}$ atom, the least-motion syn-approach of the oxygen is chosen in this case to give the syn-adduct (Fig. 3b).

The energy barrier for the anti-addition is $5.16 \mathrm{kcal} \mathrm{mol}^{-1}$, while the barrier for the syn-addition is $2.92 \mathrm{kcal} \mathrm{mol}^{-1}$ at the MP2/6-311++G(3df,2p)//MP2(full)/6-311++G** level with zero point energy (ZPE) and basis set superposition error (BSSE) correction. Whereas in the model disilene-water addition reaction, the syn-addition is more favorable than the anti-addition, the preference of the two path- 
(a)

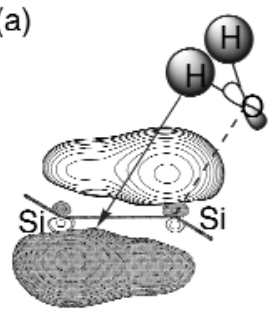

$\mathrm{C}_{\mathrm{A}}$ (b)

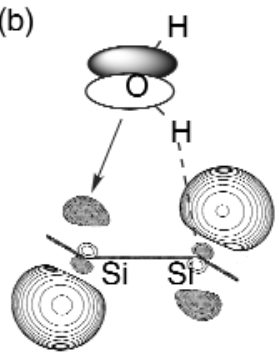

$\mathrm{C}_{\mathrm{S}}$

Fig. 2 Schematic representation of the MO interaction in the weak complexes (a) $C_{A}$ and (b) $C_{S}$.

ways in the actual reactions of disilenes with various alcohols will depend on the reaction conditions; the electronic and steric effects of substituents on disilene, the nature of the nucleophiles, solvents, etc.

An important issue of the calculations is a discovery of the intramolecular anti-addition pathway during the addition of water to disilene. Our theoretical results may give a key to understand the intramolecular anti-addition pathway found by Apeloig and Nakash [15], nevertheless the model reaction is far remote from the actual system that was studied. Preference of the anti-addition from weak complex $\mathrm{C}_{\mathrm{A}}$ would be explained by the orbital symmetry rule, instead of the relative stability of the two rotational isomers of the zwitterionic intermediates as proposed by Apeloig and Nakash [15]. The remarkable solvent effects observed experimentally are in good accord with the polar nature of the transition state for the anti-pathway $\left(\mathrm{TS}_{\mathrm{A}}\right)$ than that for the syn-pathway $\left(\mathrm{TS}_{\mathrm{S}}\right)$. Detailed experimental studies should be required to exhibit the validity of the above mechanistic view.

(a)

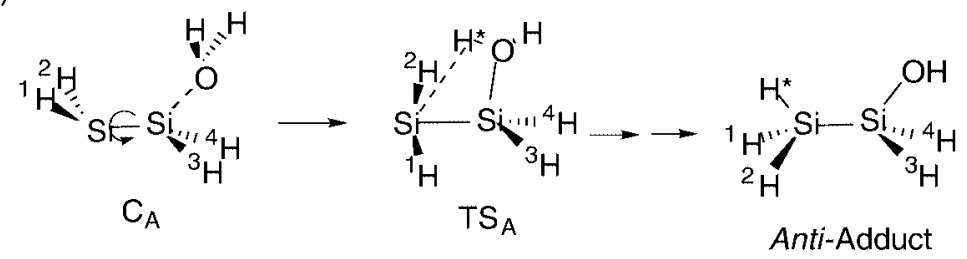

(b)

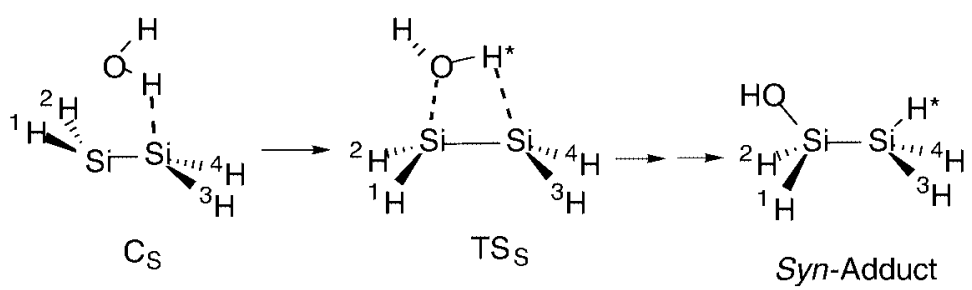

Fig. 3 Two possible pathways for the addition reaction of water to disilene.

\section{MECHANISMS OF REACTIONS OF DISILENES WITH HALOALKENES}

Recently, it has been found by West et. al. [16] and our group [10b] that disilenes react rather unusually with various haloalkanes, giving several types of products (eqs. 7 and 8).

The formation of these products is apparently suggestive of the radical nature of the reactions. Thus, these reactions are rationalized if a pair of the corresponding halodisilanyl radical and alkyl radical is formed at the first step (eq. 9); at the second step, various types of products will be formed via 

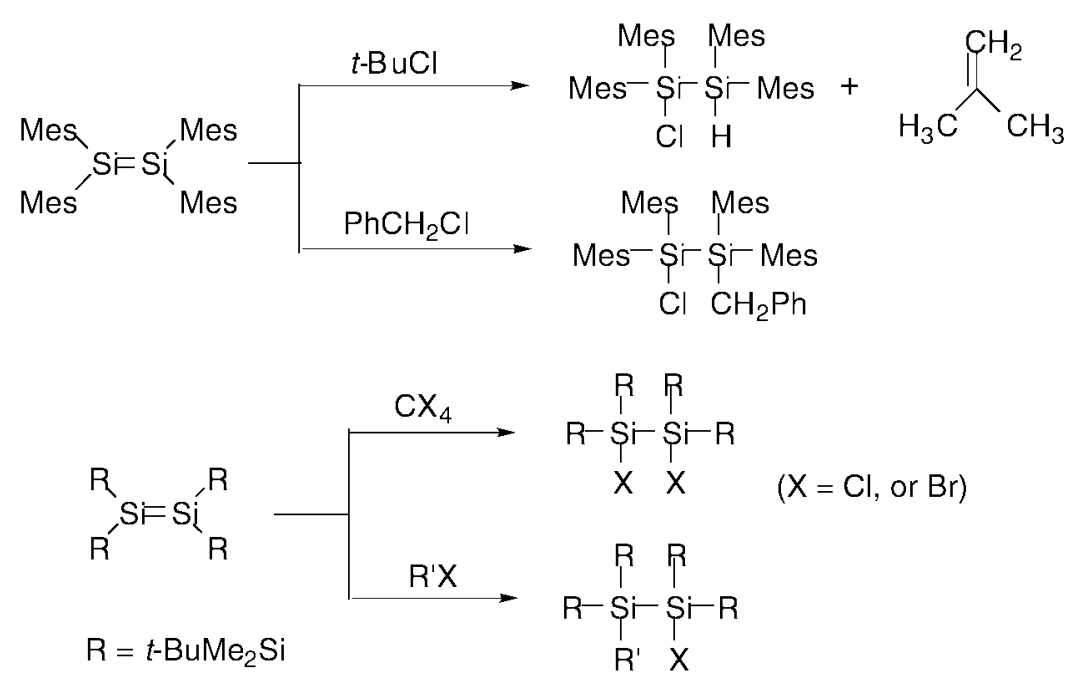

$$
\left(\mathrm{R}^{\prime}-\mathrm{X}=\mathrm{CHCl}_{2}-\mathrm{Cl}, \mathrm{CH}_{2} \mathrm{Cl}-\mathrm{Cl}, \mathrm{CH}_{3}-\mathrm{Br}\right)
$$

recombination and disproportionation of the radical pair in the cage or the second halogen abstraction of the halodisilanyl radical out of the cage.

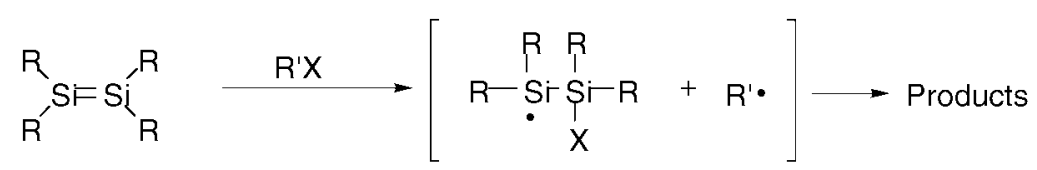

These reactions are quite exceptional because a neutral radical pair is formed from two neutral closed shell molecules; no similar reactions have been observed between alkenes and haloalkanes. Elucidation of the mechanisms of these unusual reactions of disilenes may contribute to understand the characteristics of the double bonds of Group 14 elements on the more common basis.

If the reaction of a disilene with a haloalkane proceeds via a pair of the corresponding 2-halodisilanyl radical and alkyl radical, the 2-halodisilanyl radical as a key intermediate may be observed by ESR. Actually, during the reaction of $\mathbf{7 c}$ with excess tert-butyl chloride in benzene- $\mathrm{d}_{6}$ at room temperature, an intense singlet ESR signal with several satellites due to ${ }^{29} \mathrm{Si}$ nuclei, which was assigned to $\mathbf{1 2}$, was observed (eq. 10). The reaction of $\mathbf{7} \mathbf{c}$ with $t$-butyl chloride was very slow and only $10 \%$ of $\mathbf{7 c}$ were consumed after 1 month at room temperature; the ESR signal intensity continued slowly to increase for more than half a year.

$$
7 \mathrm{c} \stackrel{t-\mathrm{BuCl}}{\mathrm{C}_{6} \mathrm{D}_{6}, \mathrm{rt}} \begin{gathered}
\mathrm{R} \\
\mathrm{R}-\mathrm{Si} \\
\mathrm{C}-\mathrm{S} i \\
\mathrm{Cl} \\
12\left(\mathrm{R}=i-\mathrm{Pr}_{3} \mathrm{Si}\right)
\end{gathered}
$$

As shown in eq. 11, the first step may proceed through either (i) the single-electron transfer from disilene to haloalkane (SET) followed by the coupling of the disilene cation radicals and chloride anion or (ii) the direct halogen abstraction of disilene from haloalkane, where the disilene is supposed to serve as a biradical.

The reactions of disilenes with haloalkanes in hexane were characterized as to obey the overall second-order rate law; first-order in disilene and first-order in haloalkane. Typically, the second-order rate constant $(k)$ for the reactions of $7 \mathrm{c}$ with chloroform was determined to be $1.6 \times 10^{-2} \mathrm{M}^{-1} \mathrm{~s}^{-1}$ in 


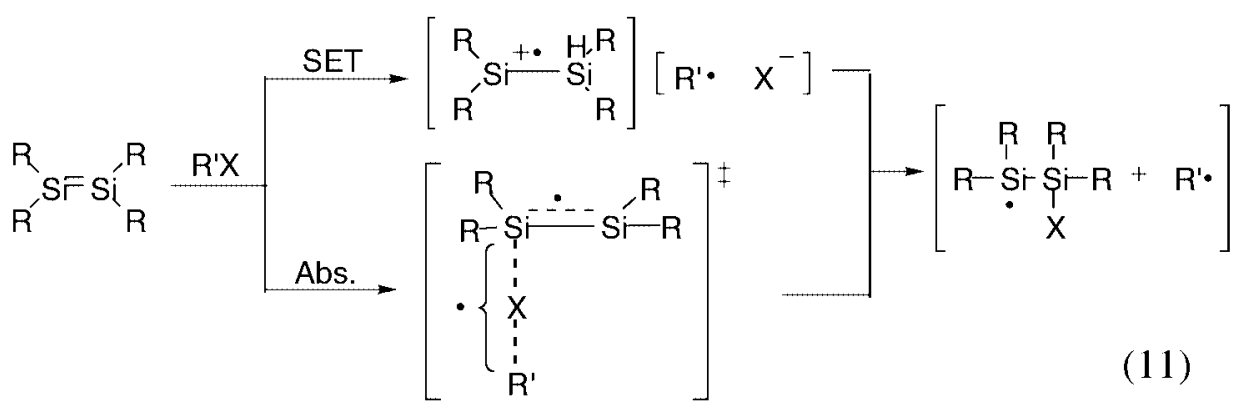

hexane at $303 \mathrm{~K} ; \Delta H=6.99 \mathrm{kcal} / \mathrm{mol}$ and $\Delta S=-43.9 \mathrm{cal} \mathrm{mol}^{-1} \mathrm{~K}^{-1}$. The $k$ value is far larger than the rate constant estimated for the single-electron transfer rate constant for this system according to the Marcus theory; $\mathrm{k}<10^{-14} \mathrm{M}^{-1} \mathrm{~s}^{-1}$ at $298 \mathrm{~K}$. The very large negative activation entropy is good in accord with the bimolecular chlorine abstraction mechanism for the first step of the reaction.

The reactions of disilenes with haloalkanes are judged to proceed via the rate-determining halogen abstraction of disilenes from haloalkanes, where the disilenes serve as biradicals. Since the role of Group 14 element unsaturated bonds as biradicals is rather exceptional, we have investigated further in detail the structure-reactivity relationship of the reactions to elucidate the transition-state structures. The second-order rate constants for the reactions of disilenes with chloroalkanes are $10^{8}-10^{14}$ times slower than the corresponding reactions for silyl radicals. These differences are understood based on the reaction enthalpies $\left(\Delta H_{0}\right)$. The chlorine abstraction reactions of silyl radicals are well known to be more than $30 \mathrm{kcal} / \mathrm{mol}$ exothermic. On the other hand, the reactions of the disilenes with chloroalkanes will be less exothermic $\left(\Delta H_{0}=-5 \sim-15 \mathrm{kcal} / \mathrm{mol}\right)$, because a Si-Si $\pi$ bond is cleaved during the reactions.

Jiang et al. have recently observed that substituent effects on the rates for the bromine abstraction of tris(trimethylsilyl)silyl radical from substituted benzyl bromide (eq. 12) were expressed by a twoparameter relationship (eq. 13), using $\sigma_{\mathrm{p}}$ for polar substituent constants and $\sigma_{\mathrm{JJ}}$ for spin delocalization constants [17]. A similar correlation using $\sigma_{\mathrm{p}}$ and $\sigma_{\mathrm{JJ}}$ constants (eq. 15) was observed for the substituent effects on the reaction rate of disilene $\mathbf{7} \mathbf{c}$ with benzyl chloride (eq. 14). The ratio of polar to spin effects, $\rho_{\mathrm{p}} / \rho_{\mathrm{JJ}}$, for the reactions of $\mathbf{7 c}$ was 0.79 , which was a little smaller than 1.09 for the reactions of $\left(\mathrm{Me}_{3} \mathrm{Si}\right)_{3} \mathrm{Si} \bullet$. The fact that the reactivities of disilenes toward benzyl chlorides are parallel to those of silyl radicals with the larger selectivity for the former suggests similar transition states between these two types of halogen abstractions. Since like other atom abstraction reactions, the transition states for halogen abstraction by a silyl radical are considered to have a linear arrangement of halide carbon-halogen-silicon atoms, a similar linear transition state will be applicable to the corresponding reactions of disilenes as shown in Fig. 4. According to the Hammond postulate, the transition state for a silyl radical should be early and reagent-like (eq. 16). On the other hand, the transition state for a disilene should be late, where the carbon-halogen bond cleavage is significantly developed (eq. 17).

$$
\begin{gathered}
\left(\mathrm{Me}_{3} \mathrm{Si}\right)_{3} \mathrm{Si}+\mathrm{CH}_{2} \mathrm{Br} \stackrel{k_{\mathrm{X}}^{\prime}}{\longrightarrow}\left(\mathrm{Me}_{3} \mathrm{Si}\right)_{3} \mathrm{SiBr}+\mathrm{x}(\mathrm{r}=0.977) \\
\log \left(\mathrm{k}_{\mathrm{X}} / \mathrm{k}_{\mathrm{H}}\right)=0.31 \sigma_{\mathrm{p}}+0.27 \sigma_{J J} \quad \mathrm{CH}_{2} \\
\log \left(\mathrm{k}_{\mathrm{X}} / \mathrm{k}_{\mathrm{H}}\right)=0.89 \sigma_{\mathrm{p}}+1.12 \sigma_{J J} \quad(\mathrm{r}=0.947)
\end{gathered}
$$


The biradical character of disilenes may be related to the $\pi$ bond energy, because the smaller the energy required to break the $\pi$ bond is, the more favorable to form the biradical. Since the $\pi$ bond energies for disilenes (ca. $25 \mathrm{kcal} / \mathrm{mol}$ ) are much smaller than usual alkenes (ca. $65 \mathrm{kcal} / \mathrm{mol}$ ), disilenes should have larger biradical character. The reason for the small $\pi$ bond energies of disilenes would be attributed to the large positive $\Delta \mathrm{E}_{\mathrm{ST}}$ of the component silylenes based on the CGMT theory [1,2]. The extension of the above discussion suggests that those alkenes that are composed of singlet carbenes may work as biradicals in their reactions. Actually, tetrafluoroethylene [1], whose $\pi$ bond energy is significantly smaller than those of the normal alkenes in relation to the large $\Delta \mathrm{E}_{\mathrm{ST}}$ of difluorocarbene has been known to work as a biradical in its [2+2] reactions with 1,3-dienes [18].

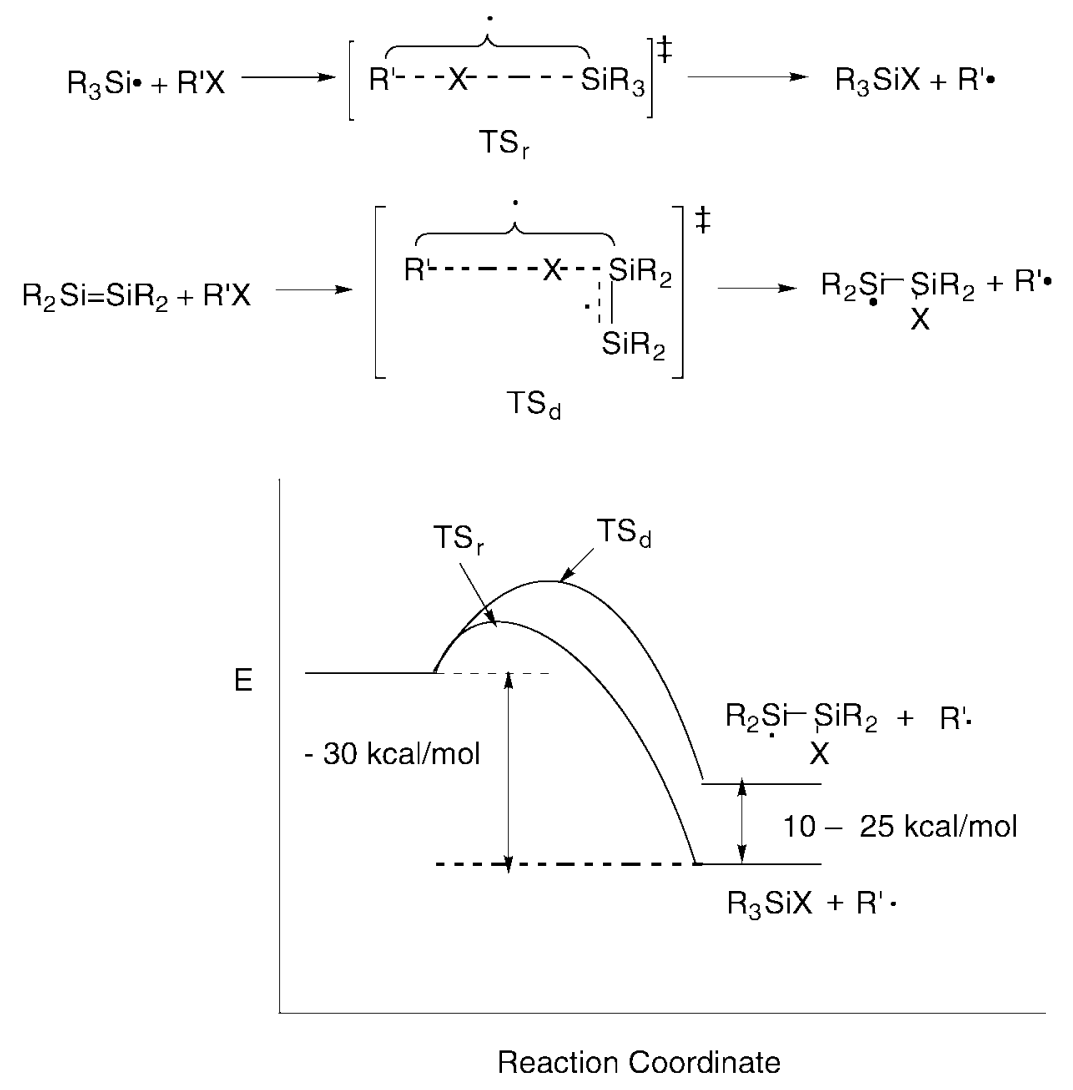

Fig. 4 Comparison of the reaction profile of the halogen abstraction of a silyl radical with that of a disilene.

\section{ACKNOWLEDGMENTS}

The author is grateful to Dr. T. Iwamoto, Dr. M. Takahashi, Prof. T. Veszprémi, Dr. C. Kabuto, Mr. T. Ishima, Mr. S. Ishida, and Mr. M. Tamura, for their active collaborations. This work was supported by the Ministry of Education, Science, Sports, and Culture of Japan (Grant-in-Aids for Scientific Research (A) No. 08404042, Scientific Research (B) No. 11440185, and Scientific Research on Priority Areas (A), "The Chemistry of Inter-element Linkage", No. 09239101).

\section{REFERENCES}

1. E. A. Carter, W. A. Goddard III. J. Phys. Chem. 90, 998 (1986); Idem J. Am. Chem. Soc. 110, 4077 (1988). 
2 (a) G. Trinquier and J.-P. Malrieu. J. Am. Chem. Soc. 109, 5303 (1987); (b) J.-P. Malrieu and G. Trinquier. J. Am. Chem.Soc. 111, 5916 (1989); (c) G. Trinquir. J. Am. Chem. Soc. 112, 2130 (1990).

3. (a) P. Jutzi, K. Kanne, C. Krueger. Angew. Chem., Int. Ed. Engl. 25, 164 (1986). (b) P. Jutzi, U. Holtmannm, D. Kanne, C. Krüger, R. Blom, R. Gleiter, I. Hyla-Krypsin. Chem. Ber. 122, 1629 (1989).

4. For reviews of stable carbenes, see: (a) A. J. Arduengo III and R. Krafczyk. Chem. Zeit. 32, 6 (1998); (b) G. Bertrand and R. Reed. Coordination Chem. Rev. 137, 323 (1994); (c) W. A. Herrmann and C. Köcher. Angew. Chem., Int. Ed. Engl. 36, 2162 (1997); (d) H. Tomioka. Adv. Carbene Chem. 2, 175 (1998).

5. For reviews of stable cyclic diaminosilylenes, see: (a) R. West and M. Denk. Pure Appl. Chem. 68, 785 (1996); (b) M. Denk, R. West, R. Hayashi, Y. Apeloig, R. Pauncz, M. Karni. In Organosilicon Chemistry II, N. Auner and J. Weis (Eds.). pp. 251-261, VCH, Weinheim (1996); (c) M. Weidenbruch. Eur. J. Inorg. Chem. 373 (1999); (d) M. Driess and H. Grützmacher. Angew. Chem. Int. Ed. Engl. 35, 828 (1998); (e) B. Gehrhus and M. F. Lappert. Phosphorus, Sulfur Silicon Relat. Elem. 124 \& 125, 537 (1997).

6. M. Kira, S. Ishida, T. Iwamoto, C. Kabuto. J. Am. Chem. Soc. 121, 9722 (1999).

7. S. Nagase and T. Kudo. J. Chem. Soc., Chem. Commun. 1392 (1984).

8. H. Suzuki, N. Tokitoh, R. Okazaki. J. Am. Chem. Soc. 116, 11573 (1994).

9. For recent reviews on $\mathrm{Si}=\mathrm{Si}$ doubly bonded compounds, see: (a) G. Raabe and J. Michl. In The Chemistry of Organic Silicon Compounds, S. Patai and Z. Rappoport, (Eds.), Part 2, Ch. 17, Wiley, New York (1989); (b) T. Tsumuraya, S. A. Batcheller, S. Masamune. Angew. Chem., Int. Ed. Engl. 30, 902 (1991); (c) R. S. Grev. Adv. Organomet. Chem. 33, 125 (1991); (d) M. Weidenbruch. Coord. Chem. Rev. 130, 275 (1994); (e) R. Okazaki and R. West. Adv. Organomet. Chem. 39, 231 (1996).

10. (a) M. Kira, T. Maruyama, C. Kabuto, K. Ebata, H. Sakurai. Angew. Chem., Int. Ed. Engl. 33, 1489 (1994); (b) T. Iwamoto, H. Sakurai, M. Kira. Bull. Chem. Soc. Jpn. 71, 2741 (1998); (c) M. Kira, S. Ohya, T. Iwamoto, M. Ichinohe, C. Kabuto. Organometallics 19, 1817 (2000).

11. T. Iwamoto, C. Kabuto, M. Kira. J. Am. Chem. Soc. 121, 886 (1999).

12. (a) M. Kira, T. Iwamoto, C. Kabuto. J. Am. Chem. Soc. 118, 10303 (1996); (b) T. Iwamoto and M. Kira. Chem. Lett. 273 (1998).

13. For cyclic disilenes reported by other research groups, see: (a) N. Wiberg, H. Auer, H. Nöth, J. Knizek, K. Polborn. Angew. Chem., Int. Ed. Engl. 37, 2869 (1998); (b) A. Grybat, S. Boomgaarden, W. Saak, H. Marsmann, M. Weidenbruch. Angew. Chem., Int. Ed. Engl. 38, 2010 (1999); (c) M. Ichinohe, T. Matsuno, A. Sekiguchi. Angew. Chem., Int. Ed. Engl. 382194 (1999).

14. For a recent review for the mechanisms of alcohol addition to disilenes, see: H. Sakurai. In The Chemistry of Organic Silicon Compounds, Z. Rappoport and Y. Apeloig (Eds.), Vol. 2, Part 1, Ch. 15, Wiley, New York (1998).

15. Y. Apeloig and M. Nakash. Organometallics 17, 1260 (1998).

16. A. D. Fanta, J. Belzner, D. R. Powell, R. West. Organometallics 12, 2177 (1993).

17. (a) X. K. Jiang, G. Z. Ji, J. R. Y. Xie. Tetrahedron 53, 8479 (1997); (b) X. K. Jiang. Acc. Chem. Res. 30, 283 (1997); (c) X. K. Jiang and G. Z. Ji. J. Org. Chem. 57, 6051 (1992).

18. (a) P. D. Bartlett. Science 159, 833 (1968); (b) P. D. Bartlett and J. J. -B. Mallet. J. Am. Chem. Soc. 98, 143 (1976).

\section{NOTE ADDED IN PROOF}

Several results reported here have appeared recently in the following journals: (1) Spiropentasiladiene: T. Iwamoto, M. Tamura, C. Kabuto, M. Kira. Science 200, 504 (2000); (2) Stereochemistry of the addi- 
tion of water to disilene: M. Takahashi, T. Veszprémi, B. Hajgató, M. Kira. Organometallics 19, 4660-4662 (2000); (3) Mechanisms of the reactions of disilenes with haloalkanes: M. Kira, T. Ishima, T. Iwamoto, M. Ichinohe. J. Am. Chem. Soc. 123, 1676-1682 (2001). 